\title{
Correction to: Interfacial Microstructural Evolution and Metallurgical Bonding Mechanisms for IN718 Superalloy Joint Produced by Hot Compressive Bonding
}

JIAN YANG ZHANG, MING YUE SUN, BIN XU, and DIAN ZHONG LI

https://doi.org/10.1007/s11663-018-1359-8

(C) The Minerals, Metals \& Materials Society and ASM International 2018

\section{Correction to: \\ Metallurgical and Materials Transactions B https://doi.org/10.1007/s11663-018-1313-9}

THE authors would like to acknowledge the financial support given by the National Key Research and Development Program (Grant Number 2016YFB0300401), National Natural Science Foundation of China (Grant Number U1508215), Key Program of the Chinese Academy of Sciences (Grant Number ZDRW-CN-2017-1), and the National Natural Science Foundation of China (Grant Number 51774265). The authors would also like to thank Bijun Xie and Yifeng Guo for their help in the experimental work.

JIAN YANG ZHANG is with School of Materials Science and Engineering, University of Science and Technology of China, Hefei, 230026, P.R. China. MING YUE SUN, BIN XU, and DIAN ZHONG LI are with Institute of Metal Research, Chinese Academy of Sciences, Shenyang, 110016, P.R. China. Contact e-mail: mysun@imr.ac.cn

The original article can be found online at https://doi.org/10.1007/ s11663-018-1313-9.

Article published online July 18, 2018 